\title{
МАЛОИНВАЗИВНЫЫЙ СПОСОБ ЛЕЧЕНИЯ БОЛЬНЫХ С НЕСРОСШИМИСЯ ПЕРЕЛОМАМИ И ЛОЖНЫМИ СУСТАВАМИ
} \begin{abstract}
MINIMALLY INVASIVE METHOD
OF TREATMENT OF PATIENTS WITH
NON-GROWING FRACTURES
AND FALSE JOINTS

$\begin{aligned} & \text { A. Ataev } \\ & \text { Lummary. Treated - } 51 \text { patients with the delayed union and nonunions } \\ & \text { of gunshot genesis extremities. }\end{aligned}$
In the main group of 31 patients was carried out surgery - bone autotransplantation with the application, developed by the authors, technology. Using a minimally invasive technique under the supervision of an electron-optical converter (EOC) in the area delayed union and nonunion, the needle is introduced flexible cannulated drill and rotary movements made cylindrical resection of scar tissue at the junction of the line break. The resulting cavity is filled with dense spongy tissue taken from the iliac crest. It is possible to reduce the period of hospital treatment by 2.6 times, and the terms of seam -1.5 times, compared with the control group.
\end{abstract}

Keywords: autoplasty, minimally invasive, nonunion, gunshot.

\section{Введение}

$\Pi$ роблема лечения несросшихся переломов и ложных суставов является одной из наиболее актуальных проблем в современной хирургии.

После огнестрельных повреждений псевдоартрозы возникают у 3,1\% раненых, а с применением высокоскоростных снарядов их частота возрастает в 8 раз [1]. Образующиеся при этом анатомо-функциональные нарушения конечностей в виде ее укорочения и деформации, контрактур смежных суставов и нейротрофических расстройств являются в 11,6-44,9\% причиной стойкой инвалидности больных $[2,3]$.
Атаев Алевдин Рашитханович

Д.м.н., ФГБОУ ВО «ДагестанскИй государственный медицинский университет» МЗ РФ (Махачкала)

drataev57@mail.ru

Атаева Лейла Алевдиновна

ФГБОУ ВО «Дагестанский государственный медицинский университет» МЗ РФ (Махачкала)

Атаев Эльдар Алевдинович

К.м.н., ФГБОУ ВО «РосСийский национальный исследовательский медицинский университет им. Н. И. Пирогова» МЗ РФ (Москва) elddar833@yandex.ru

Аннотация. Пролечен 51 больной с несросшимися переломами и ложными суставами длинных костей конечностей огнестрельной этиологии.

У 31 пациента основной группы было произведено оперативное вмешательство - костная аутопластика с применением, разработанной авторами, технологии. Используя малоинвазивную технику, под контролем ЭОП в зону несросшегося перелома или ложного сустава, по спице, вводится гибкое канюлированное сверло и вращательными движениями производится цилиндрическая резекция рубцовой ткани на стыке линии излома. Образовавшуюся полость заполняют плотной спонгиозной тканью, взятой из гребня подвздошной кости. Это позволило уменьшить сроки стационарного лечения в 2,6 раза, а сроки сращения - в 1,5 раза, в сравнении с контрольной группой.

Ключевые слова: аутопластика, малоинвазивный, несросшиеся переломы, огнестрельный.

Ведущими факторами в патогенезе замедленной консолидации являются ухудшение кровоснабжения и стойкие гемоциркуляторные нарушения в повреждённом сегменте. Сложность проблемы заключается в полиморфности патологических состояний, приводящих к появлению ложных суставов или костных дефектов, в ограниченном количестве методов лечения, способных в короткие сроки полноценно восстановить повреждённую кость и в недостаточной потенции естественной репаративной регенерации [4,5].

Даже при высококвалифицированном хирургическом лечении частота несращений переломов, образования псевдоартрозов и неправильных сращений, 
по данным современной литературы, составляет 5-10\% $[6,7]$.

После открытых повреждений частота несросшихся переломов и псевдоартрозов повышается и может достигать 30,4\% [8].

Восстановление целостности несросшейся кости в условиях хронических нарушений регенераторных процессов представляет собой трудную задачу, что связано с наличием сложных и взаимно отягощающих патологических изменений поврежденных тканей $[9,10]$.

\section{Материал и методы исслеАования}

Под нашим наблюдением находился 51 больной с несросшимися переломами и ложными суставами длинных костей конечностей огнестрельной этиологии. В возрасте от 18 до 52 лет. Все пациенты были разделены на 2 группы: основную $(n=31)$ и контрольную $(n=20)$.

Средний возраст больных составил: в основной группе $-37,0 \pm 1,2$ года; в контрольной $-36,7 \pm 1.3$ года. Из них мужчин было 49 (96,1\%), женщин - 2 (3,9\%).

По локализации в обеих группах преобладали нарушения костной регенерации в диафизарной зоне: основная 27 чел. (87\%), контрольная 17 чел. (85\%).

По форме нарушения посттравматической регенерации костной ткани преобладали несросшиеся переломы; в основной группе 17 чел (54,8\%), в контрольной группе 10 чел. (50\%).

В контрольной группе лечение осуществлялось по методике, предполагающей открытое освежение зоны замедленной консолидации или резекции ложного сустава с костной аутопластикой.

В основной группе мы применили разработанный нами способ лечения несросшихся переломов и ложных суставов длинных костей (патент РФ №2359632 от. 29.05.2007).

Для осуществления предлагаемого способа используем набор инструментов состоящий из остеоперфоратора для забора кости с поршневой системой, спиц стандартных диаметром 2 мм и гибкого канюлированного сверла. Способ осуществляли следующим образом: используя минимально инвазивную технику, под контролем электронно-оптического преобразователя (ЭОП) интраоперационно в зону несросшегося перелома или ложного сустава, с учетом топографо-анатомических особенностей сегмента и локализации имплантата-фиксатора, по центру и перпендикулярно оси сегмента, вво- дится спица диаметром 2 мм. Через минимальный разрез 0,5-1 см, по спице и под контролем ЭОП, вводится гибкое канюлированное сверло и вращательными движениями производится цилиндрическая резекция рубцовой ткани на стыке линии излома. Образовавшуюся цилиндрическую полость заполняют плотной спонгиозной тканью, взятой из гребня подвздошной кости с помощью остеоперфоратора для забора кости. Костный аутотрансплантат вводится с помощью цилиндрического тубуса и поршня. Внутренний диаметр остеоперфоратора должен превышать диаметр гибкого сверла на 1-2 мм. При наличии дефекта костной ткани данная манипуляция повторяется несколько раз, до ее заполнения. Шов на рану.

\section{Результаты исслемования и их обсу жАение}

Полученные результаты оценивались нами через 1, 3 , 6, и 12 месяцев. Рентген-контроль производился на следующий день после операции, на 28-30 день и через 2, 3, 6 и 12 месяцев. При проведении рентгенологического исследования спустя 1 месяц выявлено увеличение плотности костной ткани, наличие «ростков» костной мозоли и уменьшение остеопороза в дистальных фрагментах поврежденной кости.

Для объективной оценки состояния регионарной гемодинамики на 10-12-е сутки после операции проводили реовазографическое исследование. Всего было обследовано 10 пациентов группы контроля и 10 пациентов основной группы.

Реовазографический индекс у пациентов основной группы и группы сравнения соответственно был равен $0,45 \pm 0,017$ и 0,38 $\pm 0,26$. Пульсовой объем составили соответственно 0,62 $\pm 0,03$ и 0,53 $\pm 0,02$. Соотношение восходящей части реограммы к длительности всей волны у пациентов основной группы составило 20,37士0,41, а у пациентов контрольной группы - 15,79 $\pm 0,63$. Различия между показателями двух групп были статистически достоверны $(p<0,05)$. К моменту удаления металлоконструкции реовазографический индекс у пациентов ос-

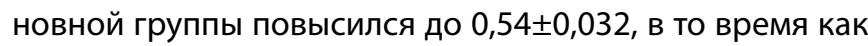
в группе сравнения этот показатель повысился лишь

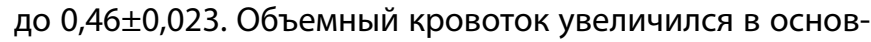
ной группе сравнения соответственно до 0,68 $\pm 0,027$

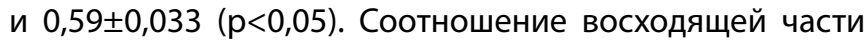
реограммы к длительности всей волны в основной группе к моменту удаления фиксатора было равно 22,42 $\pm 0,24$,

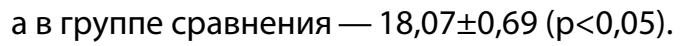

Период стационарного лечения в основной группе

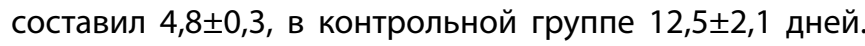
Сроки амбулаторного лечения в основной группе соста-

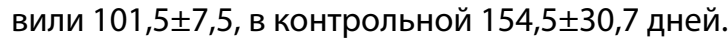




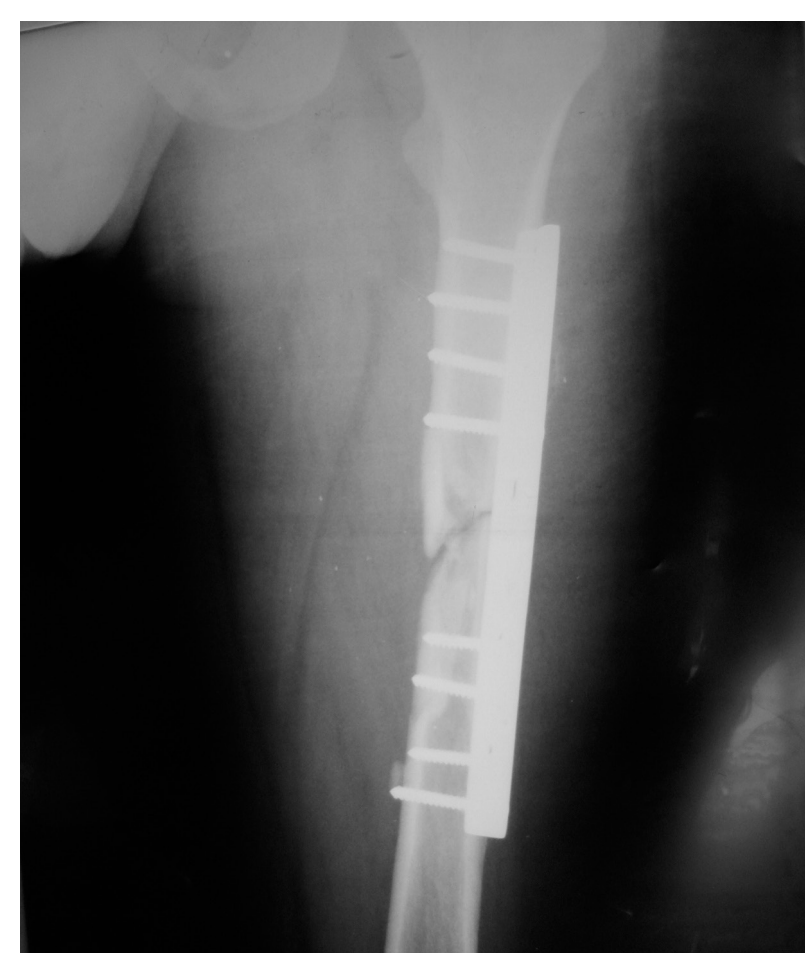

Рис. 1. Рентгенограмма правой бедренной кости на момент поступления

Анализ ближайших и отдаленных результатов лечения в сроки от 6 месяцев до 1,5 лет 21 больного основной группы и 15- контрольной группы выявил у двух больных в основной группе наличие неполной артрогенной, сгибательно-разгибательная контрактуры голеностопного сустава. Однако оба пациента нагружают конечности практически полностью. Спустя год после операции, возобновили трудовую деятельность. А в контрольной группе отмечено у 9 пациентов (у 6 - контрактура коленного и у 3 - голеностопного суставов). В основной и контрольной группах восстановление трудоспособности наступило в сроки с достоверным различием, и их снижение в основной группе, учитывая сложный характер повреждений, подтверждает наше мнение об оптимизации сроков репаративного остеогенеза на его начальной, наиболее проблемной стадии. Несращение псевдоартроза в контрольной группе отмечено у 6 больных, тогда как в основной группе - отмечено у одного больного с атрофическим ложным суставом большеберцовой кости огнестрельного генеза. Больному вновь было произведено малоинвазивное вмешательство: очищение зоны ложного сустава и аутопластика 3-мя спонгиозными столбиками.

Через два месяца было отмечено появление периостальной мозоли и восстановление стато-моторной функции конечности. В контрольной группе у шести больных после применения аутоостеопластики мы

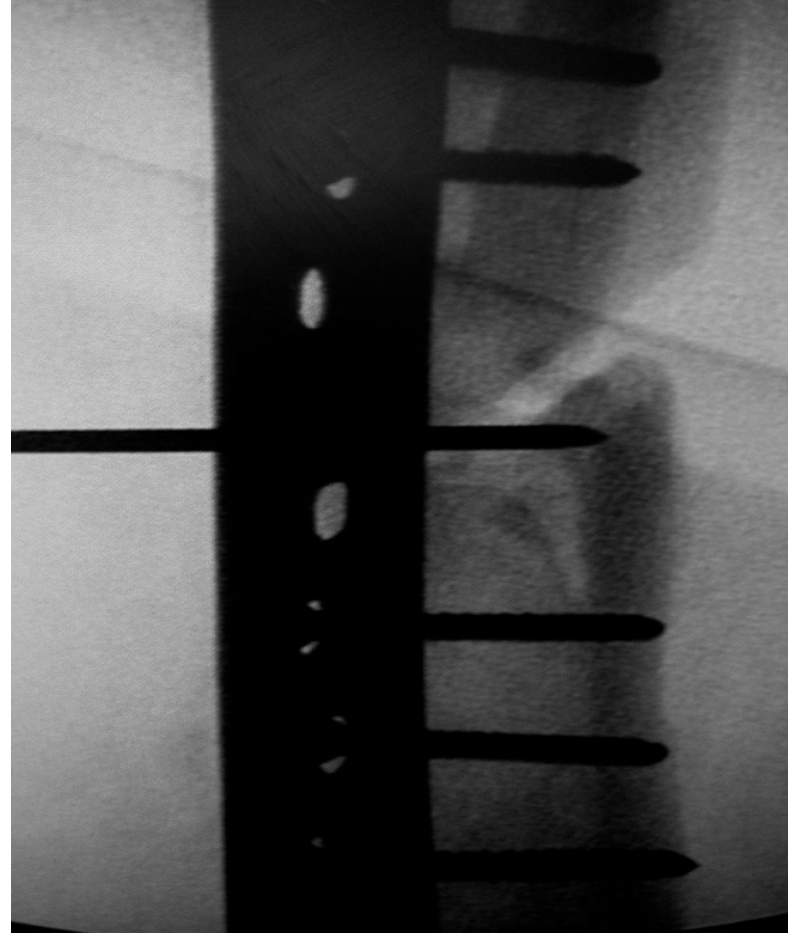

Рис. 2. Введение спицы в зону несросшегося перелома

не наблюдали положительного эффекта. По-видимому, это было связано с недостаточностью репаративно-регенерационных процессов и ухудшением васкуляризации, после открытого вмешательства. Так же у двух пациентов из контрольной группы было выявлено нагноение донорской зоны аутоостеопластики, приведшее к санации очага, дистракционному остеосинтезу по Г.А. Илизарову, ввиду наличия дефекта костной ткани после санации. Каких-либо нагноительных процессов, неконтролируемого роста костной ткани в месте применения аутотрансплантатов (спонгиозных столбиков) мы не наблюдали. Таким образом, за всё время наблюдения больных, перенесших оперативное лечение в основной подгруппе нами отмечен только один случай несращения (3.3\%), (в 10 раз меньше, чем в контрольной подгруппе -33,3\%).

\section{Пример конкретного выпо^нения способа}

Больной Я., 37 лет, поступил в стационар по поводу: Огнестрельного перелома правого бедра, состояния после накостного остеосинтеза пластиной, замедленная консолидация. Из анамнеза: 7 месяцев назад получил огнестрельное ранение правого бедра. В больнице по месту жительства была произведена первичная хирургическая обработка огнестрельного перелома и наложен стержневой аппарат АО. Через 3 недели, по заживлению раны, нами был произведен накостный остеосинтез 


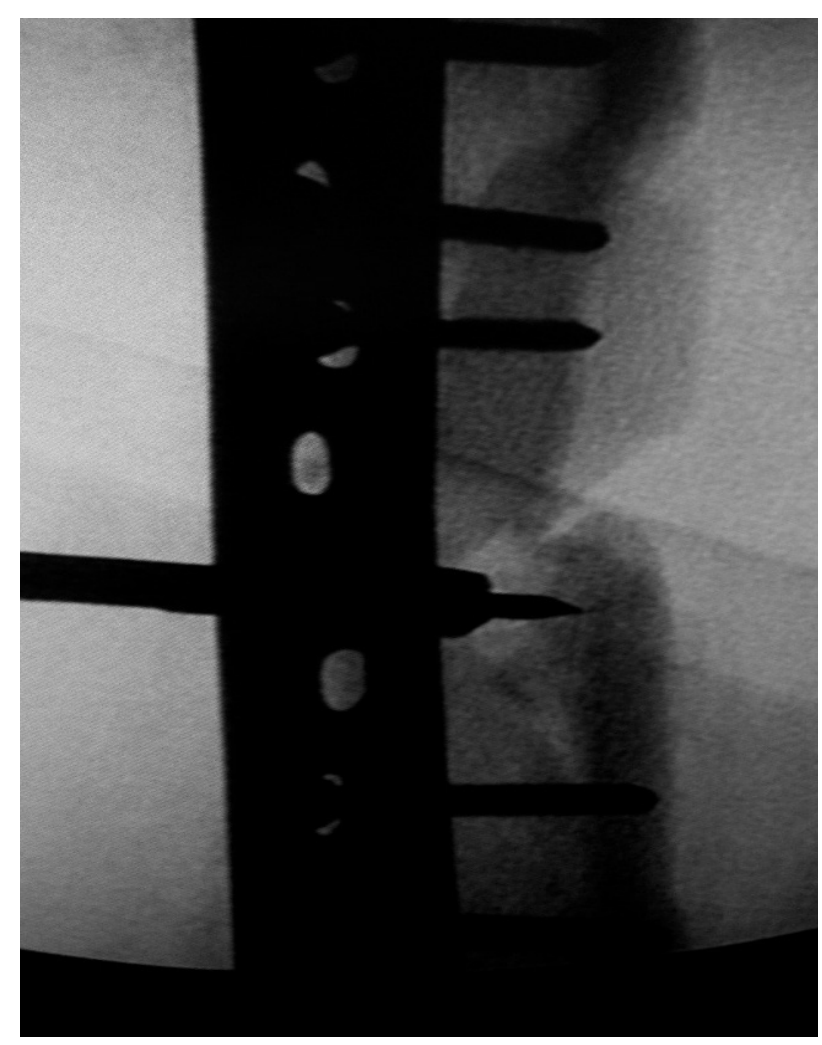

Рис.3. Введение в зону несросшегося перелома гибкого канюлированного сверла по спице

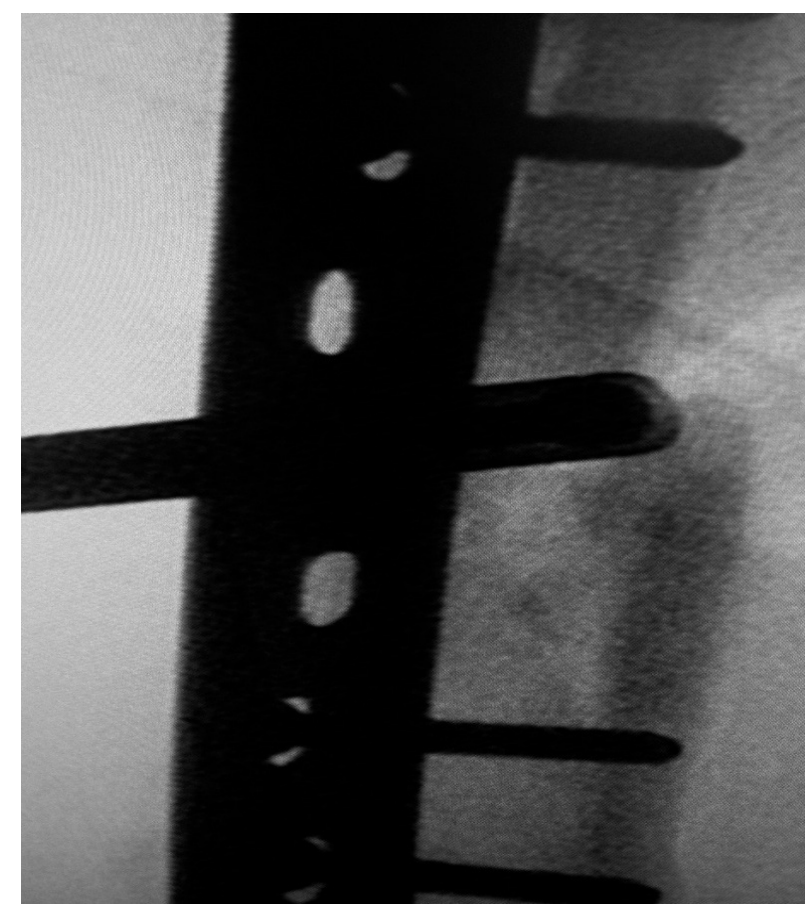

Рис. 5. Введение аутотрансплантата в заранее подготовленное ложе

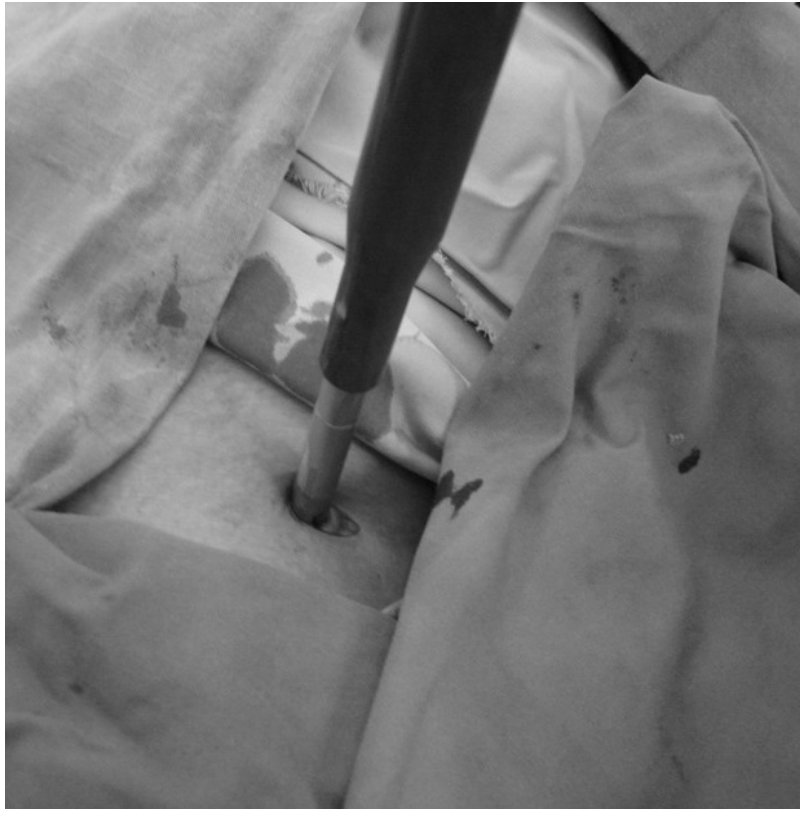

Рис. 4. Забор аутотрансплантата из гребня подвздошной кости

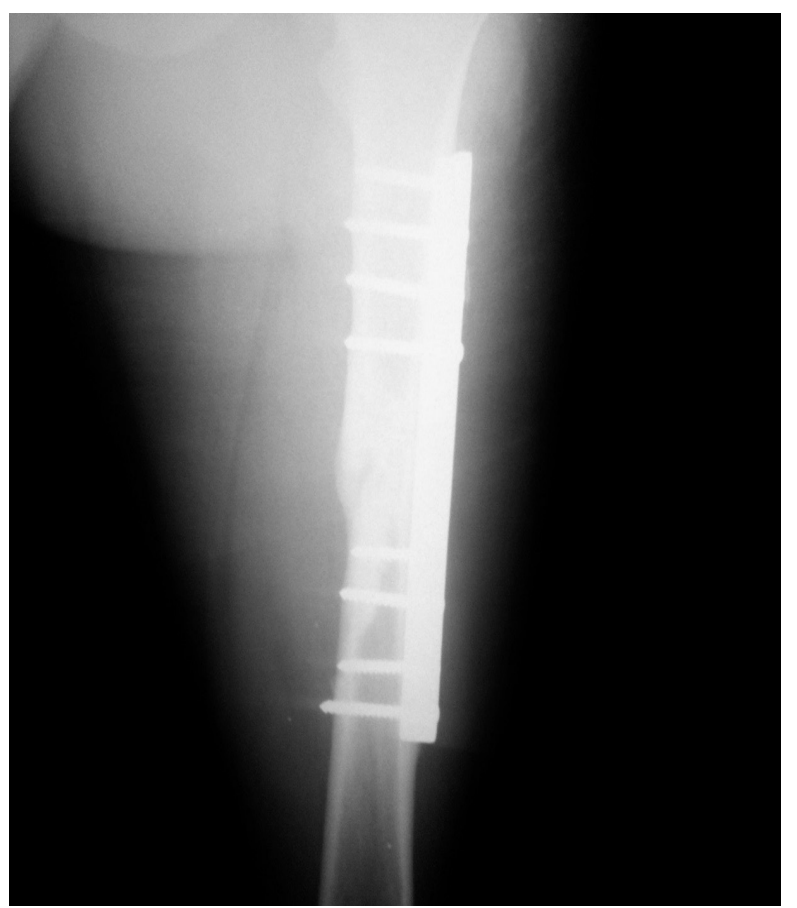

Рис. 6. Полная консолидация отломков на рентгенограмме правой бедренной кости, через 3.5 месяца 
пластиной. Заживление послеоперационной раны первичным натяжением. При поступлении жалобы на болевой синдром умеренный, усиливающий при нагрузке, отеки не выраженные. Объективно: послеоперационный рубец без признаков воспаления, кожные покровы обычной окраски, укорочения нет. На рентгенограмме правого бедра в 2-х проекциях определяется нерезко выраженный остеосклероз концов костных отломков, небольшой диастаз между отломками с признаками развивающегося остеосклероза концов отломков. Фиксация пластиной посредством 8 винтом, резорбции нет (рис. 1.)

Клинический диагноз: Огнестрельный перелом правой бедренной кости с замедленной консолидацией, состояние после накостного металлоостеосинтеза. После предоперационной подготовки, под общей анестезией, под контролем ЭОП в зону несросшегося перелома введена спица диаметром 2 мм. (рис. 2), через разрез 10 мм., по спице введено гибкое канюлированное сверло диаметром 8мм и вращательными движениями произведено освежение костных отломков (рис. 3). Произведен дополнительный разрез, длиной 10 мм., в области гребня подвздошной кости и с помощью остеоперфоратора для забора кости (внутренний диаметр 9 мм) взят костный трансплантат цилиндрической формы длиной 20 мм (рис. 4). Конец остеоперфоратора введен в рану бедра до кортикального слоя кости и аутотрансплантат плотно введен в подготовленное ложе (рис. 5). Процедура повторена дважды. Шов на рану. Послеоперационный период протекал без особенно- стей. Выписан через 5 дней. Осмотрен через 3,5 месяца, на контрольной рентгенограмме отмечается полная консолидация отломков (рис. 6). Функция конечности в полном объеме.

\section{Выво $\triangle \mathrm{b}$}

1. Иссечение основной массы рубцовой ткани на стыке отломков и аутопластика губчатой костной тканью соответствующей дефекту, усиливает васкуляризацию, вызывая формирование новых периостально-медулярных сосудистых связей, сокращает сроки сращения.

2. Малоинвазивность метода, ручное удаление рубцовой ткани не вызывает нарушения васкуляризации мягких тканей и пристеночного ожога кости, как при использовании электродрели.

3. Предлагаемый «Способ лечения несросшихся переломов и ложных суставов длинных костей», по сравнению с другими известными технологиями, при минимальной травматизации, обеспечивает сращение перелома в более короткие сроки.

4. Применение предложенного способа аутопластики с использованием малоинвазивной технологии способствует улучшению кровоснабжения и кровенаполнения в зоне нарушенной посттравматической костной регенерации, достоверному уменьшению сроков стационарного лечения в 2,6 раза, а сроки сращения - в 1,5 раза, в сравнении с контрольной группой.

\section{ЛИТЕРАТУРА}

1. Шаповалов В. М. Боевые повреждения конечностей: применение совр. технологий и результаты лечения раненных.// Травматология и ортопедия России 2006- № 2- C. 307-308

2. Гюльназарова СВ., Манаев В. И., Реутов А. И. и др. Медицинская реабилитация инвалидов с последствиями переломов костей конечностей // Человек и его здоровье: Материалы VII Российского национального конгресса. — СПб, 2002. — T. XVIII.— C. 313.

3. Акрамов И.Ш., Арушанов А. М., М. М. Жуманов, Хайдаров Н. С. Характеристика инвалидов с ложными суставами и дефектами длинных костей нижних конечностей Актуальные проблемы: Тез. материалов науч.-практ. конф. — Самарканд, 2001.-С. 61-62.

4. Омельяненко Н.П., Миронов С. П., Денисов-Никольский Ю.И., и др. Современные возможности оптимизации репаративной регенерации костной ткани. // Вестн. травматологии и ортопедии им. Н. Н. Приорова.—-2002.— № 4.- С. 85-88.

5. Tseng S.S, Lee MA, Reddi AH // Nonunions and the potential of stem cells in fracture-healing.// J Bone Joint Surgery 2008 Vol 90 N1 P. 92-98

6. Mehmet Kocaoglu, F. Erkal Bilen. Delayed Union and Nonunions// Armed Conflict Injuries to the Extremities 2011, Pages 355-373

7. Копысова В. А., Каплун В. А., Светашов А. Н., Шашков В. В. Способы восстанови - тельного хирургического лечения пациентов С дефектами и псевдоартрозами бедренной кости. Вестник травматологии и ортопедии им. Н. Н. Приорова. 2010.— № 4. — С. 65-70.

8. Фаддеев Д. И. Осложнения различных методов стабильного остеосинтеза длинных костей при политравме, их лечение и профилактика. //Диагностика и лечение политравм: Материалы Всероссийской конференции 8-10 сентября 1999. — Ленинск-Кузнецкий. — 1999. С. $279-280$.

9. Марков Д. А., Ван Кай, Левченко К. К., Стимуляция репаративного остеогенеза //Саратовский научно-медицинский Журнал. 2007.— № 3 — С. 79-84.

10. Giannoudis P. V., Kanakaris N. K. // Distal Femoral Non-union.// Practical Procedures in Elective Orthopaedic Surgery -2012.— Part 3. — P. 133-139

(с) Атаев Алевдин Рашитханович ( drataev57@mail.ru),

Атаева Лейла Алевдиновна, Атаев Эльдар Алевдинович ( elddar833@yandex.ru).

Журнал «Современная наука: актуальные проблемы теории и практики» 